\title{
PERE DE MORAGUES, MESTRE MAJOR DE L'OBRA DE LA SEU DE TORTOSA
}

\author{
MARIA VictòRIa Almuni Balada
}

SUMARI

1. L'obra de la seu a la segona meitat del segle XIV.- 2. L'inici de l'any administratiu 1382-1383 i la problemàtica sobre el nomenament d'un nou mestre major: la signatura de les capitulacions amb Pere de Moragues.- 3. El paper de Joan de Mayni com a aparellador de l'obra.- 4. El perfil professional de Pere de Moragues: imaginer, argenter i mestre major d'obres d'arquitectura.- 5. Conclusions.

La recerca documental portada a terme en els darrers anys a l'Arxiu Capitular de Tortosa, ens ha permès constatar la presència a la ciutat de diferents mestres, especialment pedrapiquers, relacionats amb l'obra de la catedral $^{1}$. Alguns d'ells havien estat ja ressenyats pel canonge Josep Matamoros en el llibre La Catedral de Tortosa $a^{2}$. D'altres, però, no havien estat encara documentats. És el cas de Pere de Moragues, imaginer i orfebre barceloní, el qual hem pogut localitzar treballant com a mestre major de la fàbrica de la catedral els anys 1382 i 1383.

\footnotetext{
'L'objectiu de l'esmentada recerca és la realització de la tesi de doctorat, dirigida per la Doctora Núria de Dalmases. El tema d'aquesta es centra en la fâbrica baixmedieval de la Seu de Tortosa, des de l'any 1345 en que es començà a preparar la renovació de la capçalera fins el 1500 .

${ }^{2}$ Josep Matamoros, La catedral de Tortosa, Tortosa, 1932.

"Anuario de Estudios Medievales", 30/1 (2000)
} 
Malgrat que l'objectiu que ens hem marcat ha estat des del principi presentar les conclusions de la nostra recerca de manera conjunta, l'interès específic d'alguns documents que constaten la presència de l'esmentat Pere de Moragues dirigint l'obra de la seu de Tortosa ens ha portat a avançar la seva publicació. La documentació localitzada ha estat, d'una banda, el registre notarial corresponent a la signatura de les capitulacions que convertiren a Pere Moragues en mestre major de les obres de la catedral gòtica. De l'altra, referències puntuals extretes de llibres de l'obra del període 1382-1383 que confirmen la seva presència a la fàbrica ${ }^{3}$.

Els documents relacionats amb Pere de Moragues aporten notícia i ens obliguen a parlar, a més, d'altres dos mestres piquers dels quals fins l'actualitat teníem escasses referències. El primer d'ells, Antoni Guarc, havia estat identificat ja per Josep Matamoros, en conservar-se la seva signatura en un plànol de planta de la seu localitzat en l'Arxiu Capitular de Tortosa, i fins ara datat pels voltants de l'any $1345^{4}$. La nostra aportació endarrereix la cronologia del mestre, donat que hem pogut documentar una primera presència seva a l'obra de la seu tortosina el 1379, treballant com a imaginer, i posteriorment el $1382 \mathrm{com}$ a rival de Pere de Moragues en l'opció al càrrec de mestre major de la fâbrica. El segon dels mestres documentats, a més de Pere Moragues, és Joan de Mayni. Arriba a Tortosa el setembre de 1382, acompanyant a Pere Moragues, per a ocupar el càrrec d'aparellador de les obres que aquest havia de dirigir. Paral-lelament a nosaltres, Josep Alanyà ha documentat aquest piquer, del qual fins ara en desconeixíem l'existència, en els Registres Reials de Cancelleria, treballant també a la seu tortosina com a mestre en la mateixa cronologia ${ }^{5}$.

\footnotetext{
${ }^{3}$ Arxiu Capitular de Tortosa (en endavant ACT), Notaris de Cabilde: Notari Pere Sunyol, llibre de l'obra de l'any 1382-1383 (en endavant ll.o. 1382-83), 15 de setembre de 1382.

${ }^{4}$ ACT, Traces i dibuixos $(620 \times 893 \mathrm{~mm})$. Dibuix a escala, fet amb tinta, d'una planta de la seu que finalment no es va realitzar. En el seu revers hi ha la inscripció mostra a portar, i en l'anvers en anthony guarc, nom del mestre al qual s'ha atribuit la seva autoria: Josep MATAMOROS, ob.cit., pp. 53-55; Josep LlUIS I GUINOVART i Victoria AlMUNI BALADA, La traça de la Catedral de Tortosa. Els models d'Antoni Guarc i Bernat Dalguaire, "Lambard. Estudis d'art medieval", IX (1996), pp. 23-37.

'Josep Alanyà I RoIG, Notícia de la seu i capitol de Tortosa a l'Arxiu de la Corona d'Aragó (segles XIV-XV), "Anuario de Estudios Medievales", XXVIII (1998), pp. 567-618.
} 


\section{L'ObRa DE LA SEU A LA SEGONA MEITAT DEL SEGLE XIV}

El projecte d'ampliació i renovació de l'edifici de la seu romànica, iniciada el 1158 i consagrada només vint anys després, el 1178, data dels temps del bisbat de Berenguer de Prats (1316-1340). Aquest prelat, un dels principals promotors del procés d'expansió i consolidació baixmedieval de l'església tortosina, determinà el 1325 l'ampliació del nombre màxim de canonges de la comunitat, la qual passà dels 12 inicials a 20. El 1340 publicà la primera de les constitucions a favor de les obres de la nova fàbrica catedralícia $^{6}$. La voluntat del bisbe, compartida pel Capítol, d'ampliar i renovar la catedral per a adaptar-la als nous temps i a les noves necessitats, no era un fet aillat. Formava part d'un programa edilici més ampli de renovació del recinte catedralici, iniciat cap a principis del segle XIV, moment en el qual la ciutat de Tortosa en conjunt vivia un procés d'expansió econòmica i urbanística important.

Les obres de la nova seu tortosina es van iniciar l'any 1346, cronologia tardana que la convertiria en una de les darreres fâbriques catedralícies de plantejament gòtic del Principat. Les capitulacions amb el primer dels mestres de l'obra, Bernat Dalguaire, foren signades el maig de 1346. La data escollida pel bisbe Bernat Oliver i el Capítol per a la col·locació de la primera pedra va ser el 21 de maig de $1347^{7}$.

Els dos primers anys de funcionament de la nova fàbrica es caracteritzaren per un ritme de treball força ràpid. El llibre de l'obra corresponent reflexa una activitat intensa en l'enderroc de patis i obertura de rases de fonamentació ${ }^{8}$. A partir de 1348 , però, aquest ritme sofrí un alentiment important. Entre 1349 i 1375 l'activitat constructiva en el sector de la nova capçalera fou poc important. Les penúries econòmiques i la inestabilitat política derivades de les seqüeles de la Pesta Negra i la Guerra dels Dos Peres degueren trasbalsar les previsions del Capítol en matèria de finançament, obligant a deixar les obres de la nova seu en un estat de semiparalització i retardar les previsions inicials.

\footnotetext{
'Ramón O’Callaghan, Episcopologio de la Santa Iglesia de Tortosa, Tortosa, 1896. ACT, Fàbrica-16.

${ }^{7} \mathrm{ACT}$, Capellanies-7.

${ }^{8} \mathrm{ACT}, 11.0 .1345-1347$.
} 
Amb l'inici del darrer quart de segle es manifesta a través de la documentació un nou impuls en la voluntat de reprendre seriosament les obres. Des de l'any 1375 el bisbe Guillem de Torrelles i el capítol catedralici feren palès en diverses constitucions el seu interès per tirar endavant les obres i superar el nivell de fonamentació en què la fâbrica es trobava. El mestre major en aquest moment, Andreu Julià, féu avançar a partir de l'any 1376 les obres de la torre i el caragol de Sant Pere, en l'extrem nord-oest de l'absis. L'obra de les capelles radials, però, va continuar alguns anys força endarrerida.

El 1382, any en el qual s'inicien en la documentació tortosina les referències a Pere de Moragues, les obres de la nova seu gòtica de la ciutat estaven força endarrerides. Els treballs es localitzaven en l'extrem nord de la capçalera, concretament en la primera de les capelles absidals, que havia de ser dedicada a Sant Pere, i l'escala de caragol contigua. De la resta de capelles radials concebudes en el projecte, algunes restaven a nivell de fonamentació, i l'espai de les altres eren encara simples solars o estaven ocupats per edificis de la canonja.

\section{L'INICI DE L'ANY ADMINISTRATIU 1382-1383}

\section{LA PROBLEMÀTICA SOBRE EL NOMENAMENT D'UN NOU MESTRE MAJOR.}

\section{LA SIGNATURA DE LES CAPITUlaCiONS AMB PERE DE MORAgUeS}

Pel que es desprèn de les anotacions del llibre de l'obra, en ser iniciat el juny de 1382 el nou any administratiu, la plaça de mestre major de la seu restava vacant ${ }^{9}$. Guerau de Montbrú, Ardiaca de Culla i obrer de fâbrica, informa a través de les seves anotacions en l'esmentat registre que els tràmits per a cobrir de nou la plaça havien començat temps enrera. El tema es trobava en aquestes dates en un moment de confusió. Dos mestres, Pere de Moragues i Antoni Guarc, competien en l'opció a l'esmentat càrrec de mestre major.

\footnotetext{
${ }^{9}$ Excepte el primer, la resta de llibres de comptabilitat o llibres de l'obra són iniciats a principis del mes de juny i acabats a darreries del mes de maig següent. El motiu que l'any natural no coincidís amb l'any administratiu era la realització al llarg del mes de juny del Capítol Anual. En aquest moment els obrers o administradors de la fâbrica donaven compte de la seva gestió davant el bisbe, prior i demés canonges. Era també ara quan es refermaven els obrers en el càrrec o n'eren nomenats altres de nous.
} 
La primera referència concreta al tema de què disposem ens situa en la segona quinzena del mes d'agost de l'esmentat 1382. L'administrador de l'obra anotà en aquest moment la despesa realitzada en trametre un missatger a Antoni Guarc, a València, demanant-li si en un plaç curt de temps vindria a Tortosa. En la carta li devia recordar que s'esperava des del mes de juny una visita seva a l'obra, la qual no havia estat materialitzada:

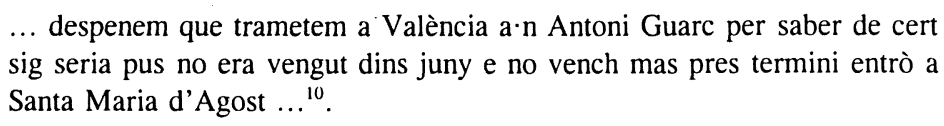

La resposta del mestre Antoni Guarc, de la qual no coneixem el contingut exacte, arribà en pocs dies a Tortosa $i$ tot seguit fou tramesa a Pere de Moragues, mestre que en aquest moment vivia i treballava a Saragossa. Així havia estat pactat prèviament entre ell i el capítol, segons es dedueix del text d'anotació de la despesa del correu:

\footnotetext{
Item trametem a Çaragoça a'n Moragues ab la resposta d'en Antoni per ço com axí era emprès que lo·y fassen saber ..."
}

Als pocs dies d'enviar resposta a través del correu capitular, Antoni Guarc realitzà l'esperat viatge a Tortosa que demanava l'administrador. Arribà a la ciutat en una data imprecisa situada entre darreries d'agost i principis de setembre. L'objectiu del mestre era negociar amb els promotors de l'obra temes relacionats amb el seu estatus i el tipus de treball que en ella havia de realitzar. L'estada a la ciutat, per a la seva dissort, fou curta. No arribà a cap acord amb el capítol, per la qual cosa tornà amb premura a València, al temps que es desvinculava de l'obra tortosina. Una referència molt breu de l'administrador per a justificar la despesa del seu viatge $\mathrm{i}$ estança a la ciutat, ens assabenta de la naturalesa real del problema. Abans de visitar Tortosa l'agost de 1382, Antoni Guarc pensava que exercia funcions de mestre major de la fâbrica de la seu. Aquesta idea, però, no era compartida pel capítol, i Antoni Guarc no els pogué convèncer. Com que cap de les dues parts abandonà la posició inicial, l'entesa no va ser possible.

\footnotetext{
${ }^{10} \mathrm{ACT}$, 11.o. 1382-1384, fol.31r, agost de 1383 .

"Ibídem.
} 
El mestre, en conseqüència, abandonà la ciutat després de cobrar els diners que li corresponien en concepte de viatge:

Item vench n'Antoni Guarc e fo aviat car no s'avengues ab nós car entenia éser mestre e per lo venir e per lo tornar e per loger de bèstia entre tot donam li .V. florins qui valen ... . LV. sous ${ }^{12}$.

El trencament de relacions entre Antoni Guarc i el capítol tortosí sembla que arribà després d'anys de col·laboració entre les dues parts en l'àmbit de la fâbrica catedralícia. La vinculació d'Antoni Guarc amb aquesta devia haver estat bastant estreta abans del 1382. El 1379, com hem indicat en un principi, és documentat per primer cop a l'obra de la seu com a mestre de imegineria, treballant en els relleus dels capitells de finestres:

\footnotetext{
Item hic fo n'Antoni Guarc mestre de imegineria que yc vench de Sent Mateu que obra los capitells de les finestres, ço és.VI. e te .I. dia de anar e altre de tornar ab .I. macip qui obra ab ell donam-li .IX. florin e tench sen per pagar per ell e per lo macip ... . LCCCCVIIII. sous ${ }^{13}$.
}

En aquest moment el mestre cobrava a estall pel seu treball. Actuava, doncs, com a professional autònom, amb cap mena de vinculació formal amb la fàbrica de no ser l'avinença puntual per esculpir aquests sis capitells. Amb posterioritat a aquesta data de 1379, però, la relació entre el mestre i la fâbrica es degué estretir. Així ho sembla indicar l'existència del ja esmentat pergamí amb la traça d'un projecte de planta de la seu, finalment modificat, en el qual hi figura la inscripció en Antoni Guarc, del qual la historiografia li ha atribuït tradicionalment l'autoria ${ }^{14}$. També de les esmentades paraules de l'administrador de fâbrica, l'agost de 1382, es desprèn que des del mes de juny s'esperava la seva visita a l'obra, la qual cosa podria voler indicar l'exercici d'alguna tasca de responsabilitat. Fos

\footnotetext{
${ }^{12}$ Ibidem.

${ }^{13} \mathrm{ACT}$, 11.0.1378-1381, fol. 49r, gener de 1379.

${ }^{14}$ Vegeu nota 4.

Aquesta era fins ara l'única referència coneguda sobre el mestre, que havia portat a Josep Matamoros a datar el seu treball a la catedral de Tortosa cap a meitat del segle XIV contemporàniament a la definició del projecte de Bernat Dalguaire. La cronologia donada per Josep Matamoros ha estat respectada pels investigadors posteriors. La documentació que ara presentem obliga a replantejar les tesis tradicionals al respecte, i situa al mestre Antoni Guarc en un període cronològic més avançat dintre el segle XIV.
} 
quina fos, però, el cas és que aquesta acabaria en el moment en què el mestre abandonà Tortosa sense haver arribat a una entesa amb els comitents de l'obra.

El 15 de setembre del mateix 1382, pocs dies després de l'incident amb Antoni Guarc, es personà a Tortosa Pere de Moragues. El mateix dia de la seva arribada signà les capitulacions que el convertien en mestre major de les obres de la seu, al temps que concretava el paper de Joan de Manyi, que l'acompanyava, com a aparellador i representant seu a la fàbrica:

Diluns, a 15 de setenbra, vench en P. Morages, mestra de la hobra, e en Johan de Mayní, aparallador, e fem la carta segons los capítols la qual pres en Pere Suyol, menor de dies, e donam li per la messió e son salari de la venguda .... .LV. sous ${ }^{15}$.

La conservació del contracte signat entre el mestre i el capítol catedralici de Santa Maria de Tortosa ens permet aprofundir en les condicions de treball de Pere Moragues i Joan de Mayni. Ens ajuda a concretar, a més, el motiu del conflicte que havia sorgit amb Antoni Guarc.

La signatura de les capitulacions es materialitzà, com hem dit, el mateix dia que els mestres havien arribat des de Saragossa. És mostra de la importància que es va voler donar a l'acte el fet que es convoqués capítol extraordinari a la Sala Capitular, a so de campana com era acostumat. Hi assistiren el Vicari General de la Diòcesi, Joan de Castres, en representació del bisbe, gairebé totes les dignitats, i cinc canonges simples ${ }^{16}$. El document, validat pel notari capitular Pere Camps, és encapçalat per la frase de affirmamento magistri operis sedis, la qual, junt amb les anotacions fetes per l'administrador en el llibre de l'obra, fa pensar que Pere de Moragues era considerat mestre de l'obra des de temps enrera. Potser el contracte signat en aquest moment era una confirmació formal, que havia de servir a més per a concretar els drets i deures de cada part. La idea es repeteix en el primer dels capítols, en el qual s'indica de nou que Pere Moragues és refermat, no nomenat, el el càrrec:

${ }^{15} \mathrm{ACT}, 11.0 .1382-1384$, fol. 31r, 15 de setembre de 1382.

${ }^{16} \mathrm{ACT}$, Notaris de Cabilde 1381-1382, notari Pere Sunyol, 15 de setembre de 1382.En aquest moment la càtedra episcopal era vacant per la mort de Guillem de Torrelles, ocorreguda el 1379. No tornaria a ser ocupada fins el 1387, moment en el qual prengué possessió del càrreg Hug de Llupià, canonge i paborde de la seu de València. 
... los honrats vicari, prior e capítol an affermat per a la obra de la seu de Tortosa, ço és, en Pere Moragues ...

L'estructura del document demostra que el contracte havia estat redactat amb prou antelació pel notari, seguint les indicacions del Capítol, en un moment en el qual aquest pensava encara en la col-laboració entre Pere Moragues i Antoni Guarc ${ }^{17}$. De la lectura del text original, considerant els fragments invalidats, es desprèn que el mestre féu modificar algunes de les condicions preestablertes pels comitents. En no ser redactat un nou document sinó només modificat l'original, en podem fer d'ell una doble lectura. D'una banda, els fragments anul-lats ens informen de les condicions que en principi volia establir el Capítol, abans que Antoni Guarc hagués decidit abandonar la negociació i es personés a Tortosa Pere de Moragues acompanyat de Joan de Mayni. De l'altra, el text fet afegir per aquests darrers permet entendre la manera com els dos mestres concebien el seu treball a la fâbrica i les condicions o drets que reivindicaven.

Pere de Moragues és qualificat en l'encapçalament del document de lapiscida, atribut que en la resta del document és substituït pel de mestre. La voluntat original del Capítol a l'hora de contractar amb ell era que treballés a peu d'obra, dirigint personalment el paredat de capelles i sectors adjacents:

Primerament, que lo dit mestre aya a éser present, al menys en paredar tot ço que e fer les capelles e tota l'altra obra...

El mestre, però, no tenia la intenció de romandre permanentment a Tortosa. Necessitava autonomia per a poder treballar en altres encàrregs, $\mathrm{i}$ tenia clar quin havia de ser el seu paper. En relació a això, va convèncer el capítol i féu modificar el text original, adequant la clàusula a la funció concreta que a opinió seva havia de complir. Segons el seu criteri i voluntat, la seva tasca no havia de consistir necessàriament en realitzar feines de

\footnotetext{
${ }^{17} \mathrm{El}$ text conservat en el manual notarial inclou les condicions originals del contracte que es van mantenir, altres d'afegides en el moment de la signatura, $i$ frases tatxades corresponents a les clausules o fragments a darrera hora invalidats. Aquest fet ens ha permès obtenir informació més completa que la que, en principi, haguessin oferit les capitulacions definitives del contracte. És per això que hem respectat en la transcripció tot el text, incloent els fragments tatxats i que hem de considerar invalidats. La transcripció del document, a l'Apèndix Documental, indica els fragments invalidats $i$ el text fet afegir per Pere de Moragues en el moment de la signatura del contracte.
} 
construcció a peu d'obra, sinó en ordenar i administrar la fâbrica del sector de capelles absidals:

... que lo dit mestre aya a éser present... en ordonar e aminstrar tota la obra de la seu desús dita.

Pere Moragues, doncs, concebia la seva relació amb l'obra més com la d'un empresari de la construcció, amb responsabilitat directa tant sobre el projecte com sobre l'organització i administració de la fâbrica, que no pas com la d'un mestre constructor encarregat de l'evolució quotidiana d'aquesta. És per aquest motiu que es va determinar des d'un principi que pogués disposar d'un mestre substitut, que ell mateix féu nomenar aparellador, que dirigís l'obra en el seu nom quan ell no hi fos. Aquest precisament va ser, com hem indicat, el principal punt de fricció entre Antoni Guarc i el capítol. El text original de les capitulacions amb Pere de Moragues especifica que l'aparellador de l'obra podia ser Antoni Guarc o un altre mestre amb la qualificació i experiència necessàries:

Item, que en absència sua aya aver un substituït, o aparalador, bo e soficient que entena la dita obra, ço és saber, n'Antoni Guarc ho altre suficient.

Amb la informació que ens aporta el llibre de l'obra ens assabenta, com hem vist, de que Antoni Guarc entenia ser mestre major. Així ho havia indicat al Capítol durant la visita per ell realitzada a darreries d'agost. La resposta dels comitents, però, li confirmà que el càrrec a què ell volia optar estava ja adjudicat a Pere de Moragues, havent estat reservat per a ell el lloc de substitut del mestre major. Aquest devia ser, doncs, el principal motiu de la desavinença entre les dues parts, que portà finalment a que el títol d'aparellador fos adjudicat a un home de confiança del mestre barceloní.

Tornant als termes del contracte amb Pere de Moragues, és evident que la condició de l'existència d'un aparellador permetia al mestre major absentar-se de l'obra sense problemes. Es més, feia possible que les seves estades a Tortosa fossin puntuals. Per a evitar conflictes posteriors relacionats amb les visites del mestre a l'obra, el capítol inclogué la condició que, en cas de trobar-se el mestre absent i ser reclamat per escrit per part del procurador, havia se personar-se immediatament a l'obra: 
Item, que si lo dit mestre serà absent e lo procurador de la obra li trametia letra que vingués que sia tengut de venir, en continent...

Pere Moragues, però, sabia de les moltes altres obligacions que tenia, les quals normalment no podia deixar d'un dia per a l'altre. És per això que de nou féu modificar el text original del contracte. En lloc d'acceptar l'obligació de traslladar-se immediatament a Tortosa en rebre el missatge del procurador, negocià i aconseguí que se li deixés un marge de 15 dies per a arribar, incloent els tres dies que costava el viatge des de Saragossa ${ }^{18}$. A més, es mantení la costum que el capítol assumís les despeses d'aquests tres dies de vinguda i altres tants de tornada:

... que sia tengut de venir ... dins .XV. dies e que prenga lo salari de .III. jorns de venir e .III de tornar e la messió.

De la mateixa manera, davant la petició del capítol que ocupés el càrrec de manera vitalícia, demanà en contrapartida que aquest darrer no pogués contractar un altre mestre major en substitució seva:

Item, que aya a tenir e continuar la dita obra de tota sa vida e que no la puxa lexar, ne lo dit capítol pusca altre mestre mudar.

En cas d'incompliment per part del mestre d'alguna de les condicions esmentades, l'obra es reservava el dret de demanar-li responsabilitats i fer-li pagar els possibles danys derivats de les seves accions:

... que sia tengut a totes messions e dampnatges que la dita obra aya a fer e sotenir per la dita rahó.

A més, el mestre restava obligat a pagar a l'obra en cas d'incompliment o perjudici mil florins d'or que serien revertits en la fâbrica:

... hoc encara que encorrega en pena de mil florins d'or aplicadors a la dita obra.

${ }^{18} \mathrm{El}$ fet que el mestre hagi de venir des de Saragossa no s'especifica en el text, però tres dies de camí corresponien en aquell moment a la distància aproximada entre aquesta ciutat Tortosa. 
En el referent al salari, era assignat al mestre mig florí d'or per cada dia treballat a peu d'obra o en un altre lloc per motiu d'aquesta. Hauria de tenir també dret a rebre una porció de capellà, assignació donada pel prior major a cada membre del capítol i beneficiat en concepte de complement per al sosteniment alimentari ${ }^{19}$ :

Item, los dits vicari, prior i capítol asignen al dit mestre per son salari per cada jorn fayner mig florí d'or.

Item, una porció de capella ultra lo dit mig flori la qual porció prengue mentre serà present. $\mathrm{E}$ en absència sua, prengua aquella lo dit substituït. .

De nou en aquest punt el mestre féu introduir una modificació. A més del salari i la porció, demanava 100 sous anuals en concepte de vestuari, independentment dels dies treballats cada any. Aconseguí també alberg franc a la ciutat que compartiria amb el seu aparellador:

Item, que aia .C. sous de vestiari lo dit mestra tots anys estant present o absent.

Item, que aia l'alberch franch per sa habitació e lo substituït o aparelador.

Especificada la remuneració salarial i els complements, totes dues parts es comprometeren de nou a respectar els termes del contracte, obligant cada part els seus bens, com era costum, al correcte compliment de les condicions. Per a evitar possibles conflictes jurisdiccionals, el capítol deixà ben clar que , en cas de conflicte, hauria de ser la jurisdicció eclesiàstica i no la civil la que resolgués els problemes:

Item, que lo dit mestre permeta complir totes les damunt dites coses e los dits vicari e prior e capítol permeten de complir al dit mestre les coses damunt dites e açò cascuna part oblic açò tots sos béns. Encara que lo dit mestre se sotmeta a for e iurisdicció del official e del veguer de la ciutat de Tortosa.

\footnotetext{
${ }^{19} \mathrm{La}$ primera referència de què disposem sobre aquesta costum es troba en la constitució a favor de les obres de la seu publicada el 1378 pel bisne Guillem de Torrelles i el capítol catedralici. En ella s'especifica l'obligació de donar cada dia al mestre unam porcionem capellam tal com fa amb els capellans comensals (ACT, Notaris de Cabilde 1378, notari Pere Sunyol, 4 de juny).
} 
Finalment, el mestre es comprometé a no dirigir altres obres dins de la ciutat o el terme de Tortosa sense consentiment del Capítol:

Item, que no puxa pendre altra obra dintre la ciutat e terme de Tortosa sens licència e consentiment dels procuradors de la dita obra.

\section{El PAPER DE JoAN DE MAYNI COM A APARELLADOR DE L'OBRA}

Totes les condicions del contracte esmentades fins ara eren incloses en els capítols que conformaven el document original que el procurador de l'obra havia fet escriure al notari prèviament a l'arribada de Pere de Moragues a Tortosa. A més de les modificacions esmentades, el mestre féu també afegir un plec de nous capítols per a concretar les responsabilitats i els drets del seu aparellador a la fâbrica de la seu de Santa Maria, Joan de Mayni. Havia quedat ja clar en els capítols anteriors que el substituït de Pere de Moragues, al qual ell fa nomenar aparalador, havia de tenir capacitat per a dirigir l'obra en nom seu, restar de manera continuada a l'obra i rebre un salari de quatre sous diaris més la porció en absència del mestre major:

Item, que en absència sua aya aver un substituït o aparalador bo e suficient que entena la dita obra ... e que estia continuament en Tortosa e prenga de salari .IIII. sous e la porció en absència del mestra.

Hem indicat també que l'aparellador tenia dret a gaudir de l'alberg franc que compartia amb el mestre major quan aquest s'estava a Tortosa:

Item, que aia l'alberch franch per sa habitació e lo substituït o aparelador.

És en els darrers capítols del document, afegits en el moment de la signatura, quan Pere Moragues fa especificar que el càrrec d'aparellador havia estat concretat en la persona de Joan de Mayni, mestre picard que havia arribat amb ell a Tortosa des de Saragossa. Tots dos mestres, qualificats de piquers en el document, devien haver treballat junts amb anterioritat. La bona entesa els hauria portat a acceptar conjuntament, donant per suposada la superioritat de Pere Moragues, la direcció de les obres de la nova catedral de Tortosa.

Joan de Mayni, present en la signatura del contracte, es comprometé amb aquest a realitzar en l'obra tot allò que li fos manat pel mestre major 
i no més. Es situava, doncs, en el referent a qüestions d'organització i de projecte, sota les úniques ordres de Pere de Moragues. Davant de possibles confusions o discrepàncies entre les dues parts contractants, mestre major $\mathrm{i}$ Capítol Catedralici, restava clar que ell havia d'obeir sempre al primer:

\footnotetext{
Item, asiga lo dit mestre per aparelador en Johan de Mayni piquart qui es present e permeta de fer e complir a la dita obra tot ço que aprés deu lo dit mestra li aministrarà e no plus.
}

El càrrec de Joan de Mayni s'estableix també en el document com a vitalici, fet que pressuposa ja des del principi una relació força estreta entre ell i la fâbrica. Comporta, a més, el compromís de no poder ser acomiadat sense el seu consentiment. Fins i tot si es succeïa un canvi de mestre major, ell hauria de continuar exercint el càrrec d'aparellador. No es contempla en aquest moment la possibilitat que, en cas de deixar l'obra Pere Moragues, Joan de Mayni pogués ocupar el càrrec de mestre major. S'especifica, això sí, que si Pere de Moragues o un altre mestre major decidís restar permanentment en la ciutat dirigint l'obra catedralícia, el jornal de Joan de Mayni seria augmentat automàticament en un sou diari, per a compensar el perjudici econòmic que li suposaria no rebre mai la porció de capellà diària:

Item, lo dit Johan permes atendrà e complir segons que desús e de tota sa vida. E lo dit vicari e capítol permet al dit Johan lo salari e ço que desus se conten e que non sia gitat de sa vida per negun altre, emperò que si lo dit mestra e altra n'i havia e estava continuament en Tortosa que rebria la dita porció e no lo dit aparalador, que en aquell cars, lo fos cresqut lo salari ço és que prengués. $V$. sous.

De l'anàlisi dels llibres de l'obra conservats es desprèn que Joan de Mayni continuà treballant en la fâbrica tortosina bastants anys. En endavant seria citat únicament com a mestra Johan ${ }^{20}$. Sabem que realitzà altres obres a la ciutat. Concretament, tenim noticia de que l'any 1383 treballava en la capella annexa a la torre de la Petja, propietat de l'Ardiaca de Culla i

\footnotetext{
${ }^{20}$ Els llibres de l'obra es refereixen amb aquest nom al mestre major fins l'any 1401, moment en el qual s'obre un periode per al qual no es conserven registres de comptabilitat i que s'allarga fins l'any 1421 .
} 
aleshores administrador de la fâbrica Guerau de Montbrú ${ }^{21}$. Col·laborà també, ignorem si dirigint, en l'obra del mur de la ciutat i en el convent de framenors ${ }^{22}$.Mercès a la recerca recent de Josep Alanyà en els registres de Cancelleria , sabem que l'abril de 1383 el rei Pere III , a Tortosa estant, li prohibí abandonar la ciutat mentre no fos acabada la capella de Sant Pere, així com fer o prendre encàrrec d'altra obra que no fos la de la seu ${ }^{23}$.

Donant per suposat que els llibres de l'obra es refereixin a ell quan parlen de mestre Joan, el podem documentar en l'obra tortosina fins l'any 1402. Malgrat ser un mestre la personalitat del qual només hem començat a perfilar, la seva tasca a Tortosa, l'estreta relació que tenia amb Pere de Moragues i els puntuals contactes amb la Corona dels quals tenim noticia, el converteixen en un arquitecte sobre el qual cal continuar investigant ${ }^{24}$.

\section{El PERFIL PROFESSIONAL DE PERE DE MORAGUES: \\ IMAGINER, ARGENTER I MESTRE MAJOR D'OBRES D'ARQUITECTURA}

Reprenent el fil del tema que centra el nostre article, l'activitat com a mestre major de la seu de Tortosa de Pere de Moragues, podem encara afegir a la documentació analitzada fins ara algunes referències puntuals que amplien la informació al respecte. Després de la signatura del contracte amb el capítol tortosí, mestre Pere Moragues féu diferents estades a la ciutat. Un cop signades les capitulacions, restà a peu d'obra tres setmanes, fins la primera quinzena d'octubre. En aquests dies degué organitzar i ultimar amb el seu substitut, Joan de Mayni, l'acabament de les obres de la capella de Sant Pere i el funcionament de la fâbrica. Sabem només d'aquest període que fou pagat per treballar diàriament i que va fer venir des de Saragossa un torn que probablement havia comprat a la fâbrica de l'església de Sant Salvador d'aquesta ciutat:

\footnotetext{
${ }^{21} \mathrm{ACT}$, ll.o. 1383-1384, juny de 1383 , fols. $43 \mathrm{r}$ i $48 \mathrm{v}$.

${ }^{22}$ ACT, 11.o.1392-93, fol.18r.

${ }^{23}$ Josep Alanyà, ob. cit., pp. 570 i 610 .

${ }^{24} \mathrm{~A}$ més de l'esmentada carta del rei Pere datada el dia 11 d'abril de 1383 , tenim referència d'una altra missiva que el rei li envia el 1387. En aquest cas, però, en desconeixem el contingut. ACT, 11.0. 1386-89, fol.26v.
} 
Item, lo torn que feu venir de Çaragoça en Moragues de compra .IIII. florins e de port .I. florí e .I. sou de Sent Salvador a la aygua que fa.. LVI. sous ${ }^{25}$.

Poc abans de la meitat del mes d'octubre el mestre es traslladà a Saragossa, pagant l'obra tres dies de viatge per a ell i una bèstia ${ }^{26}$. És possible que abans de Nadal tornés a Tortosa a controlar l'evolució de l'obra. Així en ho fa pensar una anotació de l'administrador per justificar un pagament suplementari fet a Pere Guillem, piquer, que havia estat manat pel mestre major:

Item, com en Morages venge dix que avia promés .IIII. sous a $n$ n Pere Guillem per jornal e io no lo li volgué donar sinó .III. sous e .VI. emperò dix li que li daria apart a nadal a compliment e axí per ara e que d'açí avant no li don res done li .III. florins .XXXIII. sous $^{27}$.

La vaguetat de la referència no ens permet concretar si en realitat fa una segona visita a l'obra entre octubre i desembre de 1382. Sí que ens informa, però, de l'autoritat que tenia a l'hora de determinar aspectes tant concrets com les retribucions salarials situades per sobre de la mitjana que marcava el mercat de treball local.

La següent referència al mestre data ja del juny de 1383, recentment acabada la capella de Sant Pere. En aquest cas féu també una estada llarga, aprofitada per Joan de Mayni per absentar-se. Invertí només dos dies en el viatge, la qual cosa fa suposar que no es trobava a Saragossa:

Item, vench en Morages e estech açí .IIII. jorns una setmana e l'altra altres .IIII. .... .XXXXIIII. sous

Item, .IIII. jorns entre anar e venir.II. florins e la messió de la bèstia e del matex de .VI. jorns .VI. florins .... .LXXXVIII. sous ${ }^{28}$.

És possible que a les mateixes dates o unes de properes correspongui una darrera noticia localitzada sobre el mestre en un full solt corresponent a un llibre d'obra actualment perdut. El full, sense datar, està tatxat, però

\footnotetext{
${ }^{25} \mathrm{ACT}, 11.0 .1382-1384$, s/d, fol. $16 \mathrm{v}$.

${ }^{26} \mathrm{Ibidem}$, f. $32 \mathrm{r}$.

${ }^{27}$ Ibidem, f. $34 \mathrm{v}$.

${ }^{28}$ Ibidem, f. 42 r.
} 
cap dels manuals conservats repeteixen el text que en ell hi ha ${ }^{29}$. Ens permet situar-lo en el temps de manera aproximada la indicació de la despesa per fer pintar la capella de Sant Pere, acabada el juliol de 1383, i col·locar la pedra de l'altar. El text referent a la presència de Pere Moragues ens assabenta que el mestre confeccionava en aquest moment, poc després del juliol del dit 1383, els motlles corresponents als pilars principals contigus a la capella de Sant Pere, al temps que devia concretar com havia de ser continuada l'obra de les capelles radials:

Item, en Morages sia estat açí a fer los mollos dels pilars principals apres Sent Pere costaren .V. fulles .... .XV. sous

Item, fem escombrar la hon aven a estar los peus del pilar foren .II. graneras costaren ....V. sous .VI. diners ${ }^{30}$.

Possiblement, en relació amb aquesta notícia es trobaria la de maig de 1383, segons la qual es procedia a muntar bastides per a una capella nova, que nosaltres identifiquem amb la contigua a la recentment acabada de Sant Pere, i que seria dedicada a Sant Pau ${ }^{31}$. El mestre, doncs, hauria dirigit al menys l'obra d'aquestes dues capelles absidals.

El mestratge de Pere de Moragues a la seu tortosina, datat com hem vist al menys entre setembre de 1382 i juliol de 1383 , coincideix amb un moment de maduresa en la trajectòria personal i professional de l'artista. Des que el 1908 fou presentat a Saragossa l'Ostensori dels Corporals de Daroca i identificat a Pere de Moragues com el seu autor, mercès a les publicacions de Ferran Martorell i Émile Bertaux, aquest mestre ha ocupat un lloc important, com a argenter i imaginer, en el panorama artístic baixmedieval dela Corona Catalanoaragonesa ${ }^{32}$. La primera etapa professional del mestre

\footnotetext{
${ }^{29}$ Del llibre de l'obra de cada any n'hi havia sobint més d'un exemplar, ja que es feien còpies per al capítol, per al bisbe i per a la ciutat. De manera extraordinària, del llibre de l'obra de l'any 1430-1440 es conserven tres còpies diferents de diferents mans. ACT, 11.0.1430-40.

${ }^{30} \mathrm{ACT}, 11.0 . \mathrm{s} / \mathrm{d}$, fora de registre.

${ }^{31}$ ACT,Il.o. 1382-84, maig de 1383, fol. 48r.

${ }^{32}$ Émile BÉRTAUX, Pere Moragues, argentier et imaginer, "Estudis Universitaris catalans" (1909), pp. 399-403; IDEM, Exposición retrospectiva de arte en Zaragoza, 1908. Zaragoza, 1910, pp. 399-403; Ferran MARTORELl I TRAVAL, Pere Moragues y la custoria dels Corporals de Daroca, "Estudis Universitaris Catalans" (1909), pp. 399-403; Anselm M. AlBarEDA, Pere Moragues, escultor y orfebre (segle XIV), "Estudis Universitaris Catalans", XXII (Barcelona, 1936), pp. 499-524; Núria de DALMASES I BALANYÀ, Orfebreria catalana medieval: Barcelona 1300-1500 (aproximació a l'estudi), 2 vols., Barcelona, 1989.
} 
que tenim documentada el situa a Barcelona. L'any 1358 , com a imaginer, signa contracte amb el pintor Ramon Destorrents per a tallar set imatges de fusta $^{33}$. Tres anys més tard, el 13 de setembre de 1361, apareix juntament amb el pintor Jaume Serra com a avalador de l'arquitecte Bernat Roca, en el contracte d'entallament d'un tabernacle per al convent de la Mercè de la Ciutat Comtal ${ }^{34}$.

A partir de 1366 el mestre és documentat treballant en la talla de creus de pedra destinades al monestir de Montserrat, acabades i col-locades l'octubre de $1372^{35}$. Com fa sovint, alterna aquesta amb altres obres. N'és exemple una nova col-laboració professional amb Bernat Roca el 1367.Tots dos mestres treballen conjuntament en la fabricació de la tomba de l'infant Ramon Berenguer, Comte d'Empúries, i la seva muller Maria Àlvarez ${ }^{36}$.

En aquest moment, a les acaballes de la dècada dels anys seixanta, Pere Moragues era un mestre valorat professional i socialment. No només en l'àmbit ciutadà, sinó també dintre el cercle de la Cort Reial. Ho demostra el nomenament que el rei Pere li atorgà el 1368 de familiar i domèstic $\mathrm{seu}^{37}$.

Entrada ja la dècada dels anys setanta, i consolidat el mestre com a membre del grup de privilegiats que conformava el cercle proper a la Cort Reial, tornem a trobar a Pere Moragues treballant per al Monestir de Montserrat. El 24 de febrer de 1373, signa contracte amb el prior del cenobi, Jaume de Vivers, per a confeccionar el seu sepulcre monumental ${ }^{38}$. Aquest treball, que degué ocupar part important del temps del mestre en els anys següents, és el darrer dels documentats en aquesta referit al territori del Principat. Entre 1378 i 1384 el mestre és documentat treballant a Saragossa, ciutat a la qual traslladà també el seu domicili.

El primer dels treballs que se li han documentat en el període saragossà és de nou una sepultura monumental: el sepulcre de Lop

\footnotetext{
${ }^{33}$ Núria de DALMASES, ob. cit., II, pp. 101. 202.

${ }^{34}$ Anselm Albareda, ob. cit, p. 15, doc. 35; Núria de Dalmases, ob. cit., II, pp. $101 \mathrm{i}$

${ }^{35}$ Anselm Albareda, $o b$. cit. pp. 16 a 26, docs. 36, 41, 46 i 44. Núria de Dalmases, $o b$. cit., II, pp. 102 i 202 a 204, docs. 36, 41, 43 i 44.

${ }^{36}$ Núria de DALMASES, ob. cit., p. 102.

${ }^{37}$ Ibidem, p. 203, doc. 38; Anselm Albareda, ob. cit., p. 16, doc.41

${ }^{38}$ Núria de Dalmases, ob. cit., II, pp. 102 i 205, doc. 46. Anselm AlbaredA, ob. cit., pp. 17-19, doc.46.
} 
Fernández de Luna, arquebisbe de Saragossa. És citat treballant en la capella de l'esmentat arquebisbe entre 1378 i $1381^{39}$. A partir d'aquest darrer any el mestre és documentat combinant els encàrrecs d'escultures amb el de peces d'argenteria. La primera referència que coneixem data del dia 14 de gener d'aquest any. De Saragossa estant, i com a habitador seu, atorga una àpoca de dos-cents sous a compte d'una creu d'argent que havia obrat per al llogaret de Monforte, proper a Daroca ${ }^{40}$. A partir d'aquesta data, altres referències ens permeten concretar l'activitat del mestre com a argenter a Saragossa $^{41}$. Continua al mateix temps treballant per a la Casa Reial. Aprofitant la seva estada a Saragossa, el mes de novembre de 1381, en qualitat d'imaginer, signa contracte amb el rei Pere per a traslladar la tomba de la seva mare, Teresa d'Entença, i construir un sepulcre per als infants Isabel i Sanç ${ }^{42}$. L'obra, ubicada en el convent de framenors de la ciutat, estava en procés de realització el febrer de 1382, quan el rei manà a Pere Moragues que no es mogués de la ciutat mentre no acabés la sepultura de la seva mare i familiars, a no ser per algun motiu relacionat amb la dita obra $^{43}$. El mestre s'havia compromès amb el rei a acabar la sepultura abans del mes de juny d'aquest any de 1382 , i la proximitat de la data devia fer pensar al Ceremoniós que si el mestre s'absentava no compliria el termi$\mathrm{ni}^{44}$.

L'any 1383 mestre Pere Moragues és encara documentat a Saragossa. Com a argenter d'aquesta ciutat cobra diferents quantitats per la realització d'una pica daurada i d'un segell reial $^{45}$. La darrera noticia concreta que relaciona el mestre amb la ciutat data del mes de setembre d'aquest de 1383.

\footnotetext{
${ }^{39}$ Núria de DalmaSES, ob. cit., pp. 102 i 208-210, docs. 53, 54, 57, 58 i 59.

${ }^{40}$ Núria de Dalmases, ob. cit., II, p. 102.

${ }^{+1}$ El març de 1383, com a argenter de Saragossa, cobra per la fabricació d'una pica daurada (ACA, Reial Patrimoni, registre 598, f. 106v; citat per Anselm AlBAREDA, ob. cit., p. 22; Núria de DALMASES, $o b$. cit, II, p. 102).

El mes de setembre del mateix any cobra per la confecció d'un segell reial (ACA, Reial Patrimoni, registre 600, f. 145v; citat per Anselm ALBAREDA, ob. cit, p. 22; Núria de DALMASES, $o b$. cit., II, p. 102).

${ }^{42}$ Núria de Dalmases, ob. cit., II, pp. 102 i 209, doc. 57

${ }^{43} \mathrm{El}$ rei Pere especifica en la carta que el mestre havia estat pensionat a la ciutat per l'arquebisbe Pere de Luna, que en aquest moment era ja mort.

${ }^{44}$ Anselm Albareda, ob. cit., p. 21; Ferran Martorell, ob. cit., p. 227, doc. 59; Núria de Dalmases, ob. cit., II, pp. 102 i 210 , doc. 59.

${ }^{45}$ Anselm AlBareda, ob. cit., p. 22; Núria de Dalmases, ob. cit., II, p. 102.
} 
A partir de 1384 el tornem a trobar documentat en l'àmbit del Principat. El 22 de febrer actua com a testimoni en el testament del ciutadà tarragoní Jaume Conesa, conjuntament amb el pintor Jaume Serra ${ }^{46}$. És per aquestes dates que el rei Pere li encarregà la fabricació de l'Ostensori de Daroca, peça clau que ha servit per a la identificació de Pere Moragues com un argenter de primera qualitat en el context del darrer Tres-cents ${ }^{47}$.

Mentre portava a terme la fabricació de l'ostensori, mestre Pere no abandonà altres activitats professionals, com demostra la referència al peritatge fet el 1385 ,amb el pintor Esteve Rovira, del retaule major del monestir de Sant Damià de Barcelona, pintat per Lluís Borrassà ${ }^{48}$.

Les darreres referències directes a Pere Moragues daten de 1387, moment en el qual havia acabat ja l'obra de l'ostensori ${ }^{49}$. El seu òbit degué tenir lloc poc temps després, atenent a la noticia del 18 de juny de 1388 segons la qual la seva vídua rebia l'ordre del rei Pere de no vendre la peça dels esmentats corporals. El Rei es comprometia a pagar-li, a través de Joan don Sanxo, mercader de Saragossa, els diners que faltaven per a completar la quantitat estipulada amb el seu difunt marit ${ }^{50}$.

Entre 1403 i 1411, troben encara referències documentals indirectes sobre el mestre, relacionades amb la venda de la casa que havia posseït en el Carrer Ample de Barcelona i que ara el seu fill, Marc Moragues, volia vendre ${ }^{51}$.

La consulta de la documentació de l'Arxiu Capitular de Tortosa ha permès completar el coneixement sobre els darrers anys d'activitat i vida del mestre, concretament sobre el període 1382-1383. El setembre de 1382 arribava a Tortosa en qualitat de mestre major de les obres de la Catedral, branca professional en la qual fins ara la seva activitat no havia estat concretada. Potser la carta que el rei li envià a Saragossa el febrer d'aquest mateix any, manant-li no abandonar la ciutat fins que la tomba de la seva

\footnotetext{
${ }^{46}$ Ibidem, p. 102.

${ }^{47}$ Ibidem, I, pp. 303-305.

${ }^{48}$ Ibidem, II, p. 103.

${ }^{49}$ El dia 27 de març de 1387 Joan I manà pagar 7.616 sous i 10 diners a Pere Moragues, a compte de diners que se li devien per la fabricació de l'ostensori. Núria de DALMASES, ob.cit., II, p. 103.

${ }^{50} I$ Ibidem, p. 103; Anselm Albareda, ob. cit., pp. 24-25; Ferran Martorell, $o b$. cit., pp. 231-232, doc. 81 .

${ }^{51}$ Anselm Albareda, ob. cit. pp. 523-524; Núria de DalmaSES, ob. cit., II, pp. 229, 233 i 239 , docs. 111,122 i 142 .
} 
mare no fos acabada, es trobés ja en relació amb la voluntat del mestre de dirigir les obres de la seu tortosina. Acabades o no les sepultures reials dintre el termini estipulat en el contracte, que acabava el mes de juny, el mestre es responsabilitzà de la direcció de l'obra catedralícia a partir del mes de setembre de 1382. La documentació que aportem en el nostre estudi el permet documentar com a mestre major al menys fins el juliol de 1383. El seu compromís comportà estades esporàdiques a Tortosa. Hem vist ja com en el text del contracte mestre Pere Moragues clarificava que no restava obligat a viure permanentment a Tortosa, ja que en el seu lloc ho faria Joan de Mayni. La responsabilitat que assumí, però, l'obligava a estar en contacte directe amb la fâbrica de manera periòdica. Com a mestre major de la fàbrica tortosina, Pere Moragues féu diferents estades a la ciutat. Seguint els llibres de l'obra, hem pogut constatar la seva presència en diferents moments després del setembre de 1382, moment en el qual signa contracte.

Les darreres noticies referides a la presència de Pere Moragues a Tortosa ens situen en el moment en què l'artista és documentat a cavall entre Saragossa i Barcelona. El mes de setembre de 1383 consta encara documentat com a argenter saragossà en el cobrament per la confecció d'un segell reial. El febrer de 1384, però, consta de nou a Barcelona, actuant com a testimoni en el testament del ciutadà tarragoní Jaume Conesa.La mateixa documentació tortosina reflexa la mobilitat del mestre. Mentre l'octubre de 1382 inverteix tres dies en el viatge en venir de Saragossa, el juny de 1383 és pagat només per dos dies de desplaçament, la qual cosa indica un punt d'origen més proper. Possiblement en aquest moment es trobava a Barcelona, des d'on es traslladà a la fâbrica tortosina.

Cap noticia, llevat de la del mes de juny de 1383 , ens permet especular sobre la data fins la qual Pere Moragues es va mantenir com a mestre major de la Seu. No és fins després de la seva mort, succeïda com hem dit el entre els primers mesos de 1387 i el juny de 1388, quan tenim la certesa que Joan de Mayni, el seu substitut, ostenta el càrrec de mestre major en la fâbrica tortosina ${ }^{52}$. Tampoc la informació recentment publicada per Josep Alanyà permet clarificar el tema. Seguint la documentació per ell localitzada, endevinem un conflicte de relativa importància en la qüestió del mestratge de la seu per a l'any 1383 , moment en el qual segons els llibres

\footnotetext{
${ }^{52}$ L'any administratiu 1391-1392 l'esmentat Joan de Mayni cobra el vestiari anual reservat tradicionalment al mestre major (ACT, 11.o. 1391-92).
} 
de l'obra és encara mestre major Pere de Moragues. El dia 11 de febrer el rei Pere i la seva esposa, Sibil la de Fòrtia, recomanen a Pere Safâbrega, mestre d'obres de la ciutat, com a director de les obres de la seu. Segons la carta que envien al Capítol, el mestre que aquest havia contractat, del qual no citen el nom, havia deixat les obres. La recomanació de Pere Safâbrega, seguint el text de la missiva, tenia un doble aval. El rei especifica que,a més de dirigir les obres de la ciutat, havia estat ja en anys anteriors mestre major de les obres de la seu. Els llibres de l'obra conservats, però, no es fan ressò del seu mestratge a la seu ${ }^{53}$.

Les paraules del Ceremoniós, seguint a Josep $A$ 'snayà, semblen informar entre línies d'un conflicte entre la Universitat i el Capítol catedralici en el referent al mestratge de les seves obres. Mentre la primera volia que el seu mestre ho fos també de les obres de la catedral, el segon cercava l'opció contrària: que el mestre major de la fâbrica de la seu fos l'encarregat de dirigir a la vegada les obres municipals ${ }^{54}$.

De les paraules del rei es desprèn que l'obra de la seu no tenia en aquest moment, febrer de 1383, mestre contractat. La informació que nosaltres recollim dels llibres de l'obra, però, es contradiu amb aquesta hipòtesi, donat que fins el juny de 1383 tenim certesa exacta dels mestratges de Pere de Moragues i Joan de Mayni. Cap la possibilitat que el rei no fos partidari de la participació de Pere Moragues en la fâbrica tortosina, per la qual cosa ignorés conscientment aquesta en no tenir la seva aprovació. En tot cas, la recomanació feta a favor de Pere Safâbrega no va tenir l'efecte desitjat. Els registres de comptabilitat ho demostren, ja que el seu nom no apareix referenciat en els anys posteriors a 1383 . Una segona carta reial datada a la mateixa Tortosa el 22 d'abril de 1383, només dos mesos després de l'anterior, referma la informació extreta d'aquests. A través d'ella ens assabentem del manament que el Ceremoniós fa a Joan de Mayni, al qual qualifica com a fidel seu i obrer de la fàbrica catedralícia, de no abandonar la ciutat fins que sia acabada la capella de Sant Pere ${ }^{55}$. El conflicte pel mestratge, doncs, hauria estat resolt abans d'aquesta data a favor de Mayni, pressuposant possiblement això la conformitat reial en la participació de Moragues com a director i supervisor general de la fâbrica.

\footnotetext{
${ }^{53}$ Els llibres de l'obra no es fan ressò d'aquest mestratge.

${ }^{54}$ Josep ALANYÀ, ob. cit., pp. 576-577 i 609, doc.3

${ }^{55}$ Josep AlaNYÀ, Ibídem, doc. 4.
} 


\section{CONCLUSIONS}

A manera ja de conclusió, cal remarcar el fet que l'activitat de Pere de Moragues a la seu Tortosina ens presenta al mestre, al menys en la darrera etapa de la seva trajectòria professional, com a mestre d'obres d'arquitectura. Aquesta activitat, sumada a les ja conegudes com a imaginer i orfebre, enriqueix el concepte que sobre ell es tenia fins ara. El presenta com un mestre en arts, un professional amb formació plural i prestigi consolidat en diferents àmbits de l'activitat artística. La concessió de les tasques de direcció de l'obra de la seu tortosina degué ser resultat del prestigi que el mestre s'havia anat creant al llarg de la segona meitat del tres-cents com a artista pluridisciplinar. Pere de Moragues era ja el 1382 un professional madur, amb experiència demostrada al servei de comitents poderosos. La seva estreta vinculació amb la Monarquia era per sí sol un aval important. Tot plegat, el capítol de Sant Maria de Tortosa devia pensar que amb ell aconseguiria donar a l'obra de la nova catedral una empenta que permetés finalitzar al menys l'obra de les capelles radials del presbiteri.

La presència a Tortosa d'altres mestres barcelonins com ara Bernat Roca, amb el qual Pere Moragues col-labora sovint, o Consolí Blanc, estretament vinculat també a l'àmbit cortesà, demostra que l'activitat de Pere de Moragues a la ciutat no ha de ser entesa com un fet aillat ${ }^{56}$. Les referències a aquests mestres, entre els quals mestre Pere pren en aquest moment protagonisme, i d'altres que encara estan per localitzar, han de servir per a incorporar definitivament a Tortosa en el circuit d'activitat artística baixmedieval de la Corona Catalanoaragonesa. El recorregut de Pere Moragues estableix els vèrtex d'un triangle delimitat per les ciutats de Barcelona, Saragossa i Tortosa, entre els quals les relacions comercials, polítiques i artístiques són intenses. Les referències localitzades són exemple,

\footnotetext{
${ }^{56}$ Possiblement es tracta de Bernat Roca el mestre que, l'any 1375-1376, visita la fàbrica tortosina i dina a casa del mestre de l'obra. El registre de comptabilitat el cita com a mestre Rocha (ACT, 1l.o. 1375-1376, fol. 61v). El 1388 el tormen a trobar relacionat amb la ciutat. En una carta datada el 31 de gener, el rei Joan I li demana que es trasllade a Tortosa ecompanyat per altres mestres per a mirar de construir una sèquia de rec a l'Ebre (Josep ALANYÀ, ob. cit., p. 608, doc. 2).

A Consolí Blanc el trobem també relacionat amb la seu de Tortosa a través de la Casa Reial. El 2 d'abril de 1382, de València estant, el rei Pere III ordena al mestre, com a argenter reial, que fassi el tavernacle o custòdia d'argent per a la catedral de Tortosa (Núria de DALMASES, ob. cit., II, p. 36).
} 
a més, de la importància del paper de la Corona, i en concret del Ceremoniós, en el complex panorama que conforma l'avantguarda de l'activitat artística en aquest darrer quart del segle XIV. Pere de Moragues, en aquest context, ens apareix fins el darrer moment com a artista estretament lligat a la monarquia, i a la vegada com a director d'una de les obres arquitectòniques importants que en aquest moment es portaven a terme en el Principat.

Cal, d'altra banda, no oblidar les referències que amb la informació actual no podem acabar de clarificar. La preocupació de la monarquia per influir en la decisió del capítol a l'hora de decidir el mestratge de l'obra de la seu de Tortosa en febrer de 1383, la presència de Joan de Mayni, mestre picard arribat a Tortosa de la ma de Pere Moragues, les rivalitats amb el mestre valencià Antoni Guarc, són també aspectes importants que, units als anteriors, esdevenen cap d'una madeixa conformada per un complex entrellat de relacions entre mestres i tallers que, en una part important, encara desconeixem. 


\section{APÈNDIX DOCUMENTAL}

1382, setembre, 15 .

El capítol de la Catedral de Santa Maria de Tortosa i el mestre Pere de Moragues signen les capitulacions que converteixen aquest darrer en mestre major de la fàbrica de la seu gòtica, i a Joan de Mayni en aparellador al seu servei.

ACT, Registres Notarials de Cabilde 1381-82.

De affirmamento magistri operis sedis.

Noverint universi. Quod nos Johannes Castris thesaurarius vicarius sede vacante Michael Cirera prior, Petrus Baiuli archidiaconus, Dominicus Meseguerii decanus, Andreas Costo precentor, Petrus Garreti infirmarius, Geraldus de Monte Bruno archidiaconus de Culla, Bernardo Company succentor, Guillelmus Pineda, Arnaldus Burgues, Dominicus Çanahuy, Johannes de Nogaria, Berengarius Serrat et Raymundus de Villafrancha, canonici ecclesie dertusensis presentes convocati ad Capitulum ad sonum campane pro ut moris est in ecclesia antedicta Capitulum convocari congregatique pro Capitulo et Capitulum facientes pro infrascripto negocio in domo capitulati ipsius ecclesie ex una parte. Et nos Petrus Moragues e Johannes de Mayni lapiscide ex altera parte convenimus et promitimus inter nos super opera et fabricacione sedis dertusensis facere et servare omnia et singula que continentur in capitulis que notario infrascripto dedimus in scriptis que huiusce publice scripture duximus annotanda quorum tenor fideliter hic insertus talis est. En nom de Deu e de Madona Santa Maria amen. Los honrats vicari prior e capitol han affermat per a la obra de la seu de Tortosa.

En nom de Déu e de Madona Sancta Maria, amen. Los honrats vicari, prior e capítol an affermat per a la obra de la seu de Tortosa, ço és en Pere Moragues, en la manera seguent. 
Primerament, que lo dit mestre aya a éser present almenys en paredar tot ço que e fer les capelles e tota l'altra obra' ${ }^{1}$ en ordonar e aminstrar tota la obra de la seu desús dita².

Item, que en absència sua aya aver un substitut/o aparalador/ bo e soficient que entena la dita obra ço és saber N'Anthoni Guarc ho altre suficient ${ }^{3}$ e que estia continuament en Tortosa e prenga de salari - IIII- s. e la porció en absència del mestra $^{4}$

Item, que si per aventura la obra s'accava per ell o per son substituït que el sia tengut de tornar aquella a ses propies messions.

Item, que si lo dit mestre serà absent e lo procurador de la obra li trametia letra que vingués, que sia tengut de venir en continent ${ }^{5}$ dins $\mathrm{XV}$ dies e que prenga lo salari de $\cdot$ III - jorns de venir e de $\cdot$ III - de tornar e la messiót.

Item, que haya a tenir e continuar la dita obra de tota sa vida e que no la puxa lexar ne lo dit capítol puxa altre mestra mudar?

Item, que si lo contrari feya que sia tengut a totes messions e dampnatges que la dita obra aya a fer e sotenir per la dita rahó oc encara que encorrega en pena de mil florins d'or aplicadors a la dita obra.

Item, los dits vicari, prior e capítol asignen al dit mestre e per son salari per cada jorn fayner mig flori d'or.

Item, una porció de capellà ultra lo dit mig florí la qual porció prengua mentre serà present $e$, en absència sua, prengua aquella lo so substituït per ço quel aya lo e sufucuent e açò ultra lo salari que ab los damunt dits se convendrà ${ }^{8}$ desús és escrit.

Item, que aia $\cdot C \cdot s$ de vestiari lo dit mestra tots anys estant present o absent.

Item, que aia l'alberch franch per sa habitació e lo substituït o aparelador'.

\footnotetext{
'almenys en paredar tot ço que e fer les capelles e tota l'altra obra, invalidat a l'original.

${ }^{2}$ en ordonar...desús dita, text afegit per Pere de Moragues en el moment de la signatura del contracte.

${ }^{3}$ ço és saber N'Anthoni Guarc ho altre suficient, invalidat a l'original.

${ }^{4}$ e que estia...absència del mestra, text afegit per Pere de Moragues en el moment de la signatura del contracte.

'en continent, invalidat a l'original.

'dins XV dies...e la messió, text afegit per Pere de Moragues en el moment de la signatura del contracte.

${ }^{7}$ ne lo dit capítol puxa altre mestra mudar, text afegit per Pere de Moragues en el moment de la signatura del contracte.

${ }^{8}$ ab los damunt dits se convendrà invalidat a l'original.

'desús és escrit ... substituit o aparelador, text afegit per Pere de Moragues en el moment de la signatura del contracte.
} 
Item, que lo dit mestre permeta complir totes les damunt dites coses e los dits vicari e prior e capítol permeten de complir al dit mestre les coses damunt dites e açò cascuna par obliç açò tots sos béns. Encara que lo dit mestre se sotsmeta a fer e iurisdicció del official e del veguer de la ciutat de Tortosa.

Item, que no puxa pendre altra obra dintre la ciutat e terme de Tortosa ses licència e consentiment dels procuradors de la dita obra.

Item, asiga lo dit mestre per aparelador en Johan de Mayni piquart, que és present, e prometa de fer a complir a la dita obra tot ço que aprés deu lo dit mestra li administrar e no plus.

Item, lo dit Johan per mes atendra e complir segons que desús e de tota sa vida. E lo dit vicari e capítol promet al dit Johan lo salari e ço que desús se conten e que non sia gitat de sa vida per negun altre, enperò que si los dit mestra e altra ni avia e estància continuament en Tortosa que rebria la dita porció e no lo dit aparalador que en aquell cars lo fos cresqut lo salari ço és que prengés $\cdot \mathrm{V} \cdot \mathrm{s} .{ }^{10}$.

\section{RÉSUMÉ}

La recherche documentaire menée à terme les dernières années à l'Archive Capitulaire de Tortosa, nous a permís de constater la prèsence de différents maîtres artisans dans cette ville, surtout des tailleurs de pièrre rattachés aux travaux de la cathédrale. Certains d'entre eux avaient été dejà cités par le chanoine Josep Matamoros dans son livre La catedral de Tortosa. D'autres, par contre, on n'avait aucune documentation jusqu'aujordui. C'est le cas de Pere de Moragues, sculpteur et orfèvre barcelonais qui a pu être localisé comme maître d'oeuvre des travaux de la cathedrale de Tortosa les années 1382 et 1383.

Malgré que notre objectif a été dès le debut celui de présenter dans l'ensemble les conclusions de notre recherche, l'intérêt spécifique de quelques documents qui établissent la prèsence du dit Pere de Moragues en dirigéant les travaux du siège de Tortosa nous a menés à avancer sa publication.

La documentation trouvée a été, d'un côté, les actes notariaux correspondants à la signature des accords grâce auxquels Pere Moragues est devenu maître d'oeuvre de la cathédrale gothique de Tortosa. De l'autre, des reférences précises issues des livres des travaux pendant le période 1382-1383 confirment sa présence dans le chantier.

Les documents concernant Pere de Moragues apportent des informations et nous obligent à parler aussi de deux autres maîtres tailleurs dont jusqu'à présent on en savait très peu. Au premier, Antoni Guarc, l'avait déjà identifié Josep Matamoros, sa signature étant restée dans un plan de base de la cathedrale trouvé à l'Archive Capitulaire de Tortosa et daté autour de 1345, jusqu'à maitenant. Notre apportation retarde la chronologie du maître,

${ }^{10}$ Les dues darreres clàusules foren afegides per Pere de Moragues en el moment de la signatura del contracte. 
puisqu'on a pu connaître sa prèmiere présence dans le chantier de Tortosa en 1379, où il travaillait comme sculpteur et ensuite en 1382 comme concurrent de Pere de Moragues pour la place de chef de chantier.

Le deuxième des maîtres documentés, en plus de Pere de Moragues, est Joan de Mayni. Il accompagne Pere de Moragues lors de son arrivée à Tortosa au mois de septembre de 1382 pour être aide-architecte de la construction qu'il devait diriger.

\section{SUMMARY}

The documented research, carried out during the last years in the Chapter Archive in Tortosa, has hallowed us to verify the presence in the town of some master craftsmen, specially stone-cutters, who are related with the works in the cathedral. Some of them had already been pointed out by canon Josep Matamoros in La Catedral de Tortosa. Others, however, had not been reported yet. That is the case of Pere de Moragues who was an imagery sculptor and goldsmith from Barcelona and whom we have discovered working as major master in the workshop of the Tortosa catedral in 1382-1383.

From the very beginning our objective has always been to explain the conclusions of our research as a whole; nevertheless, the specific interest of some documents, wich verify the presence of the above mentioned Pere Moragues directing the works in the cathedral of Tortosa, led us to publish them in advance. On the hand, the documents corresponding to the signature of Pere Moragues's contract as the major master on the works of the Gothic Catedral have been found in the notary registrations; on the other hand, some specific references have been taken from the books registering the work in the period 1382-1383 and which confirm his presence in the workshop.

The documents related with Pere Moragues introduce new information and make us talk about two other stone-cutter masters, of whom we had very little reference. One of them is Antoni Guarc, who had already been identified by Josep Matamoros as his signature was in the plant pan of the cathedral. The plan was found in the Chapter Archive in Tortosa and, up now, it has been dated by 1345 . Our contribution delays the master's chronology since we have been able to notice a first presence of his in the works of the Cathedral of Tortosa in 1379, working as imagery maker; and later in 1382 as rival of Pere Moragues as major master in the workshop. The second stone-cutter master is Joan de Mayni. Joan de Mayni arrived in Tortosa in September 1382. He arrived together with Pere Morages in order to be quantity surveyor in the works his companion was to direct. 